\title{
ANALISIS EFISIENSI PEMASARAN DAN MUTU GULA AREN DI KABUPATEN KUANTAN SINGINGI
}

\author{
Analysis of the Efisiensi Marketing and Quality of Palm Sugar \\ in the Kuantan Singingi Regency
}

\author{
Siti Muslimah, Evy Maharani, Susy Edwina \\ Jurusan Agribisnis Fakultas Pertanian Universitas Riau \\ siti195imah@gmail.com/085358923531 \\ [Diterima Agustus 2017; Disetujui November 2017]
}

\begin{abstract}
Palm sugar is a product derived from palm juice water treatment are already known by the general public. Palm sugar can be used as processed food ingredients, can be used as a medicine and can be used as business venture opportunities. The purpose of this study was to analyze the level of marketing efficiency and recognize quality palm sugar according to retailers and end customers in Kuantan Singingi. The study was conducted in April-December 2016. The research method used survey method and sampling craftsmen census method as many as 11 respondents. The results showed that the marketing channel there is two palm sugar Custom-retailer-consumer end; Craftsmen palm sugar-end consumers. Value marketing efficiency on the channel I was $10.79 \%$ and the efficiency of marketing channels II is $8.80 \%$. Palm sugar marketing more efficient channel of distribution II because the process is shorter than the first channel and marketing channel II was able to spend with low. Description of quality of palm sugar by craftsmen, retailers and end customers meets the criteria that can be seen from the National Quality Standards, namely: the color "brown" aroma "typical" flavor "very sweet" and form "round concave.
\end{abstract}

Keywords: Efficiency, Marketing, Quality, Palm Sugar

\begin{abstract}
ABSTRAK
Gula aren merupakan produk turunan dari pengolahan air nira aren yang sudah dikenal oleh masyarakat umum. Gula aren dapat digunakan sebagai olahan bahan makan, dapat digunakan sebagai bahan obat dan dapat digunakan sebagai bisnis peluang usaha. Tujuan penelitian ini adalah menganalisis tingkat efisiensi pemasaran gula aren dan mengetahui mutu gula aren menurut pedagang pengecer dan konsumen akhir di Kabupaten Kuantan Singingi. Penelitian dilakukan pada bulan April-Desember 2016. Metode penelitian yang digunakan adalah metode survei dan penarikan sampel pengrajin menggunakan metode sensus yaitu sebanyak 11 responden. Hasil penelitian menunjukkan bahwa saluran pemasaran gula aren ada dua yaitu Pengrajin gula aren-pedagang pengecer-konsumen akhir; Pengrajin gula aren-konsumen akhir. Nilai efisiensi pemasaran pada saluran I adalah $10,79 \%$ dan efisiensi saluran pemasaran II adalah $8,80 \%$. Pemasaran gula aren yang lebih efisien pada saluran II karena proses pendistribusiannya lebih pendek dibanding saluran I dan saluran pemasaran II mampu mengeluarkan biaya dengan sekecilnya. Deskripsi mutu gula aren menurut pengrajin, pedagang pengecer dan konsumen akhir sudah memenuhi kriteria yang dapat dilihat dari Standar Mutu Nasional yaitu: warna "coklat", aroma "khas", rasa "sangat manis" dan bentuk "bulat cekung".
\end{abstract}

Kata Kunci: Efisiensi, Pemasaran, Mutu, Gula Aren.

\section{PENDAHULUAN}

Pembangunan ekonomi didalam pembangunan nasional jangka panjang di
Indonesia mempunyai sasaran utama mencapai keseimbangan antara sektor pertanian dan industri. Keseimbangan tersebut dapat tercapai apabila kondisi perekonomian atau industri 
yang maju didukung oleh sektor pertanian yang tangguh (Soekartawi, 2001). Sebagai penggerak pembangunan pertanian, agroindustri diharapkan dapat memainkan peranan penting kegiatan pembangunan daerah dalam sasaran pemerataan pembangunan ekonomi.

Industri pengolahan komoditas pertanian selain mengolah hasil pertanian juga mempunyai tujuan yaitu untuk memperoleh keuntungan guna mempertahankan kelangsungan usahanya. Salah satu hasil pertanian yang dapat dipergunakan dan dimanfaatkan dalam industri pengolahan adalah dari tanaman pohon aren, dari pohon aren ini semuanya dapat dimanfaatkan mulai dari akar, batang, ijuk, buah, pelepah, hingga airnya. Salah satu bagian pohon aren yang akan dimanfaatkan adalah air nira. Air nira yang dihasilkan dari bunga jantan pohon aren yang dikumpulkan terlebih dahulu dalam sebuah bumbung bambu. Nira tersebut dapat diolah menjadi gula aren yang dikenal dengan nama gula merah yang memiliki rasa manis dan enak.

Produksi aren pada tahun 2013 di Provinsi Riau sebanyak 22 ton dan lahan yang sudah digunakan 29 Ha (BPS Provinsi Riau, 2015). Dimana terdapat dua Kabupaten yang menghasilkan komoditi aren dan diolah menjadi gula aren di Provinsi Riau yaitu Kabupaten Rokan Hulu pada tahun 2013 sebanyak 14 ton dengan lahan yang telah digunakan $12 \mathrm{Ha}$ dan Kabupaten Kuantan Singingi produksi aren sebanyak 8 ton dengan lahan yang telah digunakan sebanyak 17 Ha (BPS Provinsi Riau, 2015). Berdasarkan dari data kedua Kabupaten tersebut lahan yang paling banyak digunakan adalah di Kabupaten Kuantan Singingi namun produksi aren yang dihasilkan belum maksimal.

Salah satu Kabupaten di Provinsi Riau yang masih melakukan budidaya pohon aren adalah di Kabupaten Kuantan Singingi. Aren yang berada di Kabupaten Kuantan Singingi memiliki kualitas air nira yang cukup bagus, dan dapat di terima oleh masyarakat. Pengrajin biasanya menjual produk aren ini dalam bentuk produk olahan gula aren. Konsumen yang membeli gula aren secara langsung kepada produsen dengan harga $\mathrm{Rp} 20.000 / \mathrm{Kg}$. Kemasan yang digunakan oleh pengrajin untuk membungkus gula aren tersebut menggunakan kemasan daun pisang kering dimana 1 bungkus gula aren terdiri dari 4 keping gula aren dan penjualan 3 bungkus gula aren kemasan dijual dengan harga Rp.10.000 (setiap $1 \mathrm{~kg}$ gula aren kemasan sama dengan 8 bungkus).

Pemasaran gula aren yang dilakukan dari pengrajin dijual ke pedagang pengecer dengan harga Rp.20.000/Kg, pedagang pengecer menjual kembali ke konsumen di pasar dengan harga Rp.26.000/Kg. Dalam memasarkan gula aren di Kabupaten Kuantan Singingi, pengrajin masih menghadapi beberapa kendala, yang menyebabkan gula aren yang dijual harganya masih mahal yaitu karena sulit untuk mendapatkan bahan baku, sehingga produksi gula aren yang dihasilkan masih sangat terbatas dan pangsa pasar untuk gula aren hanya mampu untuk memenuhi kebutuhan pasar Kabupaten Kuantan Singingi. Proses pembuatan gula aren masih dilakukan dengan cara yang sangat sederhana dan masih sangat tradisional yaitu dengan memanfaatkan warisan dari orang tua para pengrajin, sehingga mutu gula aren yang berada di Kabupaten Kuantan Singingi masih beragam, sehingga menyebabkan kalah saing dengan produk gula merah yang lain.

Berdasarkan uraian di atas maka dapat dirumuskan permasalahan yaitu: bagaimana tingkat efisiensi pemasaran gula aren dan bagaimana mutu gula aren menurut pedagang pengecer dan konsumen akhir di Kabupaten Kuantan Singingi. Tujuan dari penelitian ini adalah menganalisis tingkat efisiensi pemasaran gula aren dan mengetahui mutu gula aren menurut pedagang pengecer dan konsumen akhir di Kabupaten Kuantan Singingi.

\section{BAHAN DAN METODE}

Penelitian ini dilakukan di Kecamatan Benai Kabupaten Kuantan Singingi, Riau. Pemilihan lokasi dilakukan secara sengaja (purposive), dengan pertimbangan bahwa lokasi tersebut merupakan sentra produksi gula aren. Penelitian dilaksanakan pada bulan April 2016 Desember 2016.

Metode yang digunakan dalam penelitian adalah metod survei, yaitu penelitian yang dilakukan melalui pengumpulan informasi dari populasi secara langsung ditempat kejadian menggunakan kuesioner dengan tujuan untuk mengetahui pendapat dari sebagian populasi yang diteliti terhadap permasalahan.

Penarikan sampel pengrajin dengan cara sensus dengan mengambil semua pengrajin 
yang ada di Kecamatan Benai, dengan jumlah 11 orang responden. Sampel pedagang sebanyak 10 responden dan sampel konsumen sebanyak 30 responden. Jenis dan sumber data yang digunakan dalam penelitian ini yaitu: data primer dan data sekunder.

Untuk menjawab tujuan pertama yaitu menganalisis tingkat efisiensi pemasaran gula aren dilakukan dengan analisis efisiensi pemasaran. Untuk menghitung efisiensi pemasaran (Soekartawi, 2005) rumusnya adalah:

$$
\begin{aligned}
& \text { Ep }=\frac{\mathrm{TBP}}{\mathrm{TNP}} \times 100 \% \\
& \text { Keterangan: } \\
& \mathrm{Ep} \quad=\text { Efisiensi pemasaran }(\%) \\
& \mathrm{TBP}=\text { Total biaya pemasaran }(\mathrm{Rp} / \mathrm{kg}) \\
& \mathrm{TNP}=\begin{array}{r}
\text { Total nilai produk yaitu harga beli } \\
\text { pada konsumen }(\mathrm{Rp} / \mathrm{kg})
\end{array}
\end{aligned}
$$

Untuk menjawab tujuan kedua yaitu mengetahui mutu gula aren menurut pengrajin, pedagang pengecer dan konsumen akhir dapat diketahui secara langsung dengan wawancara terhadap sampel pedagang pengecer dan konsumen hilir yang dianalisis secara deskriptif. Kriteria mutu gula aren meliputi warna, tesktur, aroma, rasa, kebersihan, berat, ukuran, dan lainnya.

\section{HASIL DAN PEMBAHASAN}

\section{Gambaran umum agroindustri gula aren}

Jumlah pengrajin gula aren yang berada di Kecamatan Benai, Kabupaten Kuantan Singingi yang masih terus mengelola air nira menjadi gula aren yaitu berjumlah 11 orang pengrajin, sampel pedagang sebanyak 10 orang.

Pohon aren di lokasi penelitian dapat menghasilkan air nira mencapai 21-22 liter/hari, hasil sadapan air nira dapat diolah menjadi gula aren dan bisa menghasilkan \pm 56 bungkus/hari gula aren dalam sehari produksi atau gula aren yang dihasilkan oleh pengrajin dalam setiap hari bisa mencapai $7 \mathrm{Kg}$ /hari. dalam 1 bungkus gula aren terdiri 4 keping gula aren, dari hasil penelitian untuk menghasilkan $1 \mathrm{Kg}$ gula aren terdiri dari 8 bungkus. Namun, dari jumlah produksi gula aren yang dihasilkan oleh pengrajin dalam setiap harinya, hasil olahan tersebut belum mampu untuk memenuhi kebutuhan pasar. Potensi aren yang berada di
Kecamatan Benai masih memiliki peluang yang sangat baik, akan tetapi tidak didukung dengan luas areal budidaya tanaman aren yang masih belum mencukupi dalam memproduksi gula aren.

\section{Proses produksi pembuatan gula aren}

Proses pembuatan gula aren sebagian besar biasanya hanya dilakukan oleh pengrajin. Proses pembuatannya dimulai dari penyadapan nira, penyaringan air nira, pemasakan nira, dan pencetakan gula aren. Kegiatan yang dilakukan pertama kali dalam pengolahan gula aren adalah dengan pengumpulan nira, melalui penyadapan air nira yang dilakukan pada pagi dan sore hari. Proses selanjutnya adalah pemasakan gula aren dengan mencampurkan gula yang setengah matang selama 3-4 hari. Saat proses pemasakan waktu yang digunakan 60-240 menit. Proses selanjutnya adalah pencetakan gula aren yang sudah matang. Cairan gula aren mulai dituangkan kedalam cetakan dan ditunggu hingga 10-15 menit sebelum dilepas dari cetakan. Setelah selesai pencetakan, gula aren siap untuk dikemas.

\section{Saluran pemasaran}

Saluran pemasaran merupakan proses pemasaran yang akan dilalui oleh setiap produk dari produsen hingga ke konsumen. Saluran pemasaran dapat berbentuk sederhana dan dapat pula rumit. Hal demikian tergantung dari macam komoditi, lembaga pemasaran dan sistem pemasaran (Swastha dan Irawan 1999). Panjang pendeknya saluran pemasaran tergantung dari jumlah lembaga perantara yang digunakan.

Saluran pemasaran gula aren yang ada di Kabupaten Kuantan Singingi ada dua saluran pemasaran, yaitu saluran pemasaran I pengrajin menjual ke pedagang pengecer dan langsung ke konsumen akhir yang berada di pasar Kecamatan Benai, Kabupaten Kuantan Singingi. Saluran II dari pengrajin gula aren dan langsung ke konsumen akhir. Saluran pemasaran I harga jual pengrajin ke pedagang pengecer adalah Rp.20.000/Kg, pedagang pengecer menjual ke konsumen dengan harga Rp.26.000/Kg. Saluran pemasaran II, pengrajin yang berperan langsung sebagai pedagang di pasar Kabupaten Kuantan Singingi menjual 
gula aren ke konsumen akhir dengan harga Rp.20.000/Kg.

\section{Analisis saluran pemasaran I}

Menurut Soekartawi (2005), saluran pemasaran dapat terbentuk secara sederhana dan rumit. Proses saluran pemasaran I, pengrajin menjual ke pedagang pengecer yang berperan sebagai perantara dalam memasarkan gula aren, pedagang pengecer yang berperan dalam penyediaan gula aren di pasar, dan untuk memenuhi kebutuhan gula aren pedagang pengecer sangat bergantung kepada pengrajin dalam pembelian gula aren dan tetap akan mengambil gula aren yang diproduksi setiap harinya. Berikut ini analisis saluran pemasaran I dapat dilihat pada Tabel 1 sebagai berikut.

Tabel 1. Saluran pemasaran I gula aren di Kabupaten Kuantan Singingi

\begin{tabular}{|c|c|c|c|}
\hline \multirow{2}{*}{ No } & \multirow{2}{*}{ Keterangan } & \multicolumn{2}{|c|}{ Saluran Pemasaran I } \\
\hline & & Jumlah $(\mathrm{Rp} / \mathrm{Kg})$ & $\%$ \\
\hline \multirow[t]{5}{*}{ A } & Pengrajin & 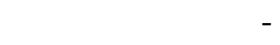 & - \\
\hline & 1. Harga jual & 20.000 & \\
\hline & 2. Biaya pemasaran & 298 & 100,00 \\
\hline & - Transportasi & 298 & 100,00 \\
\hline & 3. Penerimaan & 19.702 & - \\
\hline \multirow[t]{9}{*}{ B } & Pedagang Pengecer & & \\
\hline & 1. Harga beli & 20.000 & - \\
\hline & 2. Harga jual & 26.000 & - \\
\hline & 3. Biaya pemasaran & 2.507 & 100,00 \\
\hline & - Transportasi & 1.795 & 67,97 \\
\hline & - Biayapajakpasar & 360 & 14,36 \\
\hline & - Kemasanplastik & 460 & 18,35 \\
\hline & 4. Margin pemasaran & 6.000 & - \\
\hline & 5. Keuntungan & 3.493 & - \\
\hline \multirow[t]{2}{*}{$\mathrm{C}$} & Konsumen akhir & - & - \\
\hline & 1. Harga beli & 26.000 & \\
\hline $\mathrm{D}$ & Total biaya pemasaran & 2.805 & 100,00 \\
\hline $\mathrm{E}$ & Total margin pemasaran & 6.000 & \\
\hline $\mathrm{F}$ & Efisiensi pemasaran & - & 10,79 \\
\hline $\mathrm{G}$ & Keuntungan total & 3.195 & \\
\hline $\mathrm{H}$ & Bagian yang diterima pengrajin & - & 76,92 \\
\hline
\end{tabular}

Total margin pemasaran pada saluran pemasaran I adalah Rp.6.000/Kg yang didapat dari selisih harga yang diterima pengrajin dengan harga yang dibayar pihak konsumen. Total penerimaan bersih yang diterima pengrajin sebesar Rp.19.702/Kg. Harga jual yang dilakukan pengrajin ke pedagang pengecer yaitu Rp. $20.000 / \mathrm{Kg}$. Biaya pemasaran yang dikeluarkan oleh pedagang pengecer di Kecamatan Benai yaitu biaya transportasi sebesar Rp.1.795/Kg, biaya pajak pasar yaitu Rp.360/Kg, dan biaya kemasan plastik sebesar Rp.460/Kg. Total biaya pemasaran yang dikeluarkan oleh pedagang pengecer yaitu $\mathrm{Rp} .2 .507 / \mathrm{Kg}$ dan harga penjualan pedagang pengecer ke konsumen Rp.26.000/Kg. Total biaya pemasaran pada saluran I adalah Rp.2.805/Kg. Keuntungan bersih yang diterima pengrajin adalah Rp.3.195/Kg. Keuntungan yang diterima oleh pedagang Rp.3.493/Kg. Bagian yang diterima pengrajin yaitu sebesar 76,92\%.

Efisiensi pemasaran dapat terjadi, yaitu pertama, jika biaya pemasaran dapat ditekan sehingga keuntungan pemasaran dapat lebih tinggi; kedua, persentase perbedaan harga yang dibayarkan konsumen dan produsen tidak terlalu tinggi; ketiga, tersedianya fasilitas fisik pemasaran; dan keempat adanya kompetisi pasar yang sehat. Pada saluran pemasaran I diperoleh nilai efisiensi pemasaran gula aren sebesar $10,79 \%$. 


\section{Analisis saluran pemasaran II}

Pemasaran gula aren pada saluran II lebih pendek dibanding saluran pemasaran I, pada saluran II pengrajin menjual gula aren kepada konsumen secara langsung di pasar, dimana pada saluran pemasaran II, Pengrajin berperan juga sebagai pedagang dengan menjual gula aren di pasar Kabupaten Kuantan Singingi. Saluran pemasaran II dapat dilihat pada Tabel 2, sebagai berikut.

Tabel 2. Saluran pemasaran II gula aren di Kabupaten Kuantan Singingi

\begin{tabular}{clrr}
\hline \multirow{2}{*}{ No } & & \multicolumn{2}{c}{ Kaluran Pemasaran II } \\
\cline { 3 - 4 } & & Jumlah $(\mathrm{Rp} / \mathrm{Kg})$ & $\%$ \\
\hline A & Pengrajin & 20.000 & - \\
& 1. Harga jual & 1.759 & - \\
& 2. Biaya pemasaran & 269 & 100,00 \\
& - Pajakpasar & 491 & 15,29 \\
& - Kemasanplastik & 999 & 27,91 \\
& - Transportasi & 18.241 & 56,79 \\
& 3. Penerimaan & - & - \\
\hline B & Konsumen akhir & 20.000 & - \\
& 1. Harga beli & 1.759 & 100,00 \\
\hline C & Total biaya pemasaran & 0 & - \\
D & Total margin pemasaran & - & 8,80 \\
\hline E & Efisiensi pemasaran & 18.241 & - \\
\hline F & Keuntungan total & - & 100,00 \\
\hline G & Bagian yang diterima pengrajin & & \\
\hline
\end{tabular}

BerdasarkanTabel 2, Saluranpemasaran II, pengrajin mengeluarkan biaya pemasaranya itu biaya transportasi Rp.999/Kg, biaya pajak pasar Rp.269/Kg, dan biaya kemasan plastik Rp.491/Kg, total biayapemasaran yang dikeluarkanpengrajinadalah Rp.1.759/Kg, total penerimaan yang diterima pengrajin yaitu Rp. $18.241 / \mathrm{Kg}$. Keuntungan yang diterima pengrajin Rp.18.241/Kg, nilai efisiensi yang diterima pengrajin $8,80 \%$. Margin pemasaran pada saluran II bernilai 0. Bagian yang diterima pengrajin gula aren pada saluran II yaitu $100 \%$.

Menurut Mubyarto (1994), pemasaran untuk komoditas pertanian dalam suatu sistem pemasaran dianggap efisien apabila mampu menyampaikan hasil-hasil dari produsen kepada konsumen dengan biaya sekecil mungkin dan mampu mengadakan pembagian yang adil dari keseluruhan harga yang dibayar konsumen akhir kepada semua pihak yang ikut serta didalam kegiatan produksi dan pemasaran.

Hasil analisis dari kedua saluran pemasaran tersebut, saluran pemasaran yang lebih efisien adalah pada saluran pemasaran II dengan nilai efisiensi sebesar $8,80 \%$, karena pengrajin mampu menjualnya secara langsung kepada konsumen tanpa adanya pedagang perantara dan mampu menjualnya dengan mengeluarkan biaya pemasaran dengan sekecil mungkin.

Berdasarkan penelitian yang dilakukan oleh Maharani, Edwina, dan Kusumawaty (2011), dengan judul Pemasaran Gula Kelapa di Kabupaten Indragiri Hilir melalui Pendekatan Struktur, Perilaku \& Penampilan Pasar.Efisiensi pada saluran pemasaran 1 lebih efisien bila dibandingkan dengan saluran pemasaran 2 dan 3. Bagian yang diterima pengrajin pada pada saluran 1 adalah sebesar 0,91 pada saluran 2 sebesar 0,88 dan pada saluran 3 sebesar 0,77. Artinya semakin panjang rantai pemasaran maka semakin sedikit bahagian keuntungan yang diterima pengrajin.

\section{Mutu gula aren menurut pedagang pengecer dan konsumen di Kabupaten Kuantan Singingi}

Darmadi (2010), mutu berdasarkan International Standard Operational (ISO) 84021992 didefinsikan sebagai karakteristik menyeluruh dari suatu wujud apakah itu produk, kegiatan, proses, organisasi atau manusia, yang menunjukkan kemampuannya dalam memenuhi kebutuhan yang telah ditentukan. Kualitas gula aren telah ditetapkan dalam Standard Nasional Indonesia (SNI 01- 
3743-1995). Berikut ini analisis mutu gula aren menurut pedagang pengecer dan konsumen akhir.

\section{Mutu gula aren menurut pedagang}

Mutu gula aren yang dianggap baik menurut pedagang, adalah merupakan gambaran ataupun penjabaran tentang bagaimana mutu gula aren yang baik menurut pandangan pedagang. Adapun aspek-aspek yang dinilai yang dinilai yaitu dari segi faktor warna, tekstur, aroma, rasa, kebersihan, dan lainnya yang dapat dilihat pada Tabel 3 .

Tabel 3. Deskriptif mutu gula aren menurut pedagang

\begin{tabular}{|c|c|c|c|c|c|}
\hline No & Kriteria & $\begin{array}{c}\text { Deskriptif } \\
\text { menurut SNI }\end{array}$ & $\begin{array}{c}\text { Deskriptif mutu gula aren } \\
\text { menurut pedagang }\end{array}$ & Jumlah pedagang & $(\%)$ \\
\hline \multirow{2}{*}{\multicolumn{2}{|c|}{ 1. Warna }} & Kuning & Coklat & 6 & 60,00 \\
\hline & & $\begin{array}{l}\text { kecoklatan } \\
\text { sampai coklat }\end{array}$ & Coklat kemerahan & 4 & 40,00 \\
\hline \multirow{2}{*}{\multicolumn{2}{|c|}{ 2. Tekstur }} & - & Keras & 5 & 50,00 \\
\hline & & & Sedikit keras & 5 & 50,00 \\
\hline \multirow{2}{*}{\multicolumn{2}{|c|}{ 3. Aroma }} & Normal, khas & Sangat Khas & 7 & 70,00 \\
\hline & & & Harum & 3 & 30,00 \\
\hline \multirow{2}{*}{\multicolumn{2}{|c|}{ 4. Rasa }} & Normal, khas & Sangat manis & 5 & 50,00 \\
\hline & & & Manis & 5 & 50,00 \\
\hline \multirow{2}{*}{\multicolumn{2}{|c|}{ 5. Ukuran }} & - & Bervariasi & 5 & 50,00 \\
\hline & & & Ukuran sama semua & 5 & 50,00 \\
\hline \multirow{2}{*}{\multicolumn{2}{|c|}{ 6. Bentuk }} & Normal & Bulat cekung & 7 & 70,00 \\
\hline & & & Pipih/gepeng & 3 & 30,00 \\
\hline \multirow{2}{*}{\multicolumn{2}{|c|}{ 7. Daya tahan }} & - & $2-4$ bulan & 6 & 60,00 \\
\hline & & & 6 bulan & 4 & 40,00 \\
\hline & Kemasan & - & Daun pisang & 10 & 100,00 \\
\hline & Kebersihan & - & Bersih & 10 & 100,00 \\
\hline
\end{tabular}

Kriteria warna gula aren yang baik yaitu dimana 6 orang pedagang berpendapat memilih warna yang cenderung coklat $(60,00 \%)$ sedangkan 4 orang pedagang mengatakan gula aren yang baik adalah gula aren tersebut berwarna coklat kemerahan $(40,00 \%)$. Kriteria ini sedikit hampir sama dengan kriteria syarat mutu gula aren menurut Badan Standar Nasional gula aren dimana warna gula aren yang disyaratkan berwarna kuning kecoklatan sampai coklat.

Deskripsi gula aren dari segi tekstur bahwa ada 5 orang pedagang yang menyatakan gula aren dengan tekstur keras $(50,00 \%)$. 5 orang pedagang lainnya mengatakan untuk kualitas gula aren yang baik adalah dengan tekstur sedikit keras $(50,00 \%)$. Namun perbedaan yang dikemukakan oleh masingmasing pedagang tidak mempengaruhi didalam proses penjualan karena masih dapat diterima dipasaran.

Berdasarkan hasil penelitian 7 orang pedagang mengatakan aroma yang baik adalah dengan aroma sangat khas $(70,00 \%)$, dan 3 orang pedagang mengatakan dengan aroma yang khas. Namun berdasarkan Badan Standar Nasional (1995), deskripsi mutu gula aren yang baik jika untuk segi aroma yang baik adalah beraroma khas dan normal.

Berdasarkan hasil penelitian ada 5 orang pedagang mengatakan untuk rasa yang baik dalam kualitas gula aren dengan rasa sangat manis $(50,00 \%)$, dan ada 5 orang pedaganglagi mengatakan untuk rasa gula aren yang baik adalah manis $(50,00 \%)$. Menurut Badan Standar Nasional (1995), standar mutu gula aren yang bagus dari kriteria rasa adalah gula aren tersebut memiliki rasa normal dan khas. Deskripsi mutu gula aren dari hasil penelitian untuk kriteria bentuk, ada 7 orang pedagang $(70,00 \%)$ mengatakan gula aren yang bagus berbentuk bulat cekung, dan ada 3 orang pedagang mengatakan gula aren yang bagus adalah dengan bentuk pipih/gepeng.

Deskripsi gula aren yang selanjutnya adalah dari segi kemasan gula aren. Semua pedagang mengatakan gula aren yang berada di Kabupaten Kuantan Singingi menggunakan kemasan daun pisang. Alasan pengrajin menggunakan daun pisang adalah agar gula 
aren tersebut lebih tahan lama ketika disimpan, gula aren disimpan didalam tempat yang kering dan konsumen tidak pernah merasa rugi jika membeli gula aren yang dikemas dengan menggunakan daun pisang.

\section{Mutu gula aren menurut konsumen}

Konsumen merupakan hal yang penting dalam suatu usaha. Konsumen merupakan orang yang menggunakan suatu produk yang telah dihasilkan. Untuk membeli suatu produk, biasanya konsumen mempunyai persepsi atau pandangan terhadap produk yang dibeli dan digunakan. Semakin sering konsumen membeli produk, maka semakin jeli pula konsumen menilai suatu produk.

Mutu gula aren yang dianggap baik menurut konsumen, merupakan gambaran ataupun penjabaran tentang bagaimana mutu gula aren yang baik menurut pandangan konsumen. Adapun aspek-aspek yang dinilai sama dengan aspek-aspek yang dinilai pada pedagang yaitu faktor warna, tekstur, aroma, rasa, kebersihan, berat, bentuk, daya tahan dan kemasan. Deskripsi mutu gula aren menurut konsumen dapat dilihat pada Tabel 4.

Tabel 4. Deskripsi mutu gula aren menurut konsumen

\begin{tabular}{|c|c|c|c|c|}
\hline Kriteria & Deskriptif menurut SNI & $\begin{array}{c}\text { Deskriptif mutu gula } \\
\text { aren menurut konsumen }\end{array}$ & $\begin{array}{c}\text { Jumlah } \\
\text { konsumen }\end{array}$ & $(\%)$ \\
\hline \multirow[t]{3}{*}{ 1. Warna } & \multirow{3}{*}{$\begin{array}{l}\text { Kuning kecoklatan } \\
\text { sampai coklat }\end{array}$} & Coklat & 13 & 43,33 \\
\hline & & Coklat kemerahan & 9 & 30,00 \\
\hline & & Kemerahan & 8 & 26,67 \\
\hline \multirow[t]{3}{*}{ 2. Tekstur } & \multirow[t]{3}{*}{-} & Keras & 10 & 33,33 \\
\hline & & sedikit keras & 11 & 36,67 \\
\hline & & Mudah pecah dan masir & 9 & 30,00 \\
\hline \multirow[t]{2}{*}{ 3. Aroma } & \multirow[t]{2}{*}{ Normal, khas } & Sangat khas & 19 & 63,33 \\
\hline & & Harum & 11 & 36,67 \\
\hline \multirow[t]{2}{*}{ 4. Rasa } & \multirow[t]{2}{*}{ Normal, khas } & Sangat manis & 21 & 70,00 \\
\hline & & Manis & 9 & 30,00 \\
\hline \multirow[t]{3}{*}{ 5. Ukuran } & \multirow[t]{3}{*}{-} & Bervariasi & 9 & 30,00 \\
\hline & & Ukuran sama semua & 12 & 40,00 \\
\hline & & Ringan dan kecil & 9 & 30,00 \\
\hline \multirow[t]{2}{*}{ 6. Bentuk } & \multirow[t]{2}{*}{ Normal } & Bulat cekung & 17 & 56,67 \\
\hline & & Pipih/gepeng & 13 & 43,33 \\
\hline \multirow[t]{2}{*}{ 7. Daya tahan } & \multirow[t]{2}{*}{-} & $2-4$ bulan & 22 & 73,33 \\
\hline & & 6 bulan & 18 & 60,00 \\
\hline 8. Kemasan & - & Daun pisang & 30 & 100,00 \\
\hline \multirow[t]{3}{*}{ 9. Kebersihan } & \multirow[t]{3}{*}{-} & Bersih & 15 & 50,00 \\
\hline & & Cukup bersih & 10 & 33,33 \\
\hline & & Kurang bersih & 5 & 16,67 \\
\hline
\end{tabular}

Ada 13 orang konsumen yang menyatakan gula aren yang bagus adalah gula dengan yang warna coklat $(43,33 \%)$. Konsumen yang menyatakan warna gula aren yang bagus adalah dengan warna coklat kemerahandengan jumlah 9 orang $(30,0 \%)$. Konsumen yang memberikan pendapat kualitas mutu gula aren yang bagus adalah dengan warna kemerahan dengan jumlah konsumen yang berpendapat 8 orang $(26,67 \%)$. Kriteria mutu gula aren aren selanjutnya adalah dari segi aroma, ada 19 orang $(63,33 \%)$ menyatakan mutu gula aren yang bagus adalah dengan aroma sangat khas, dan 11 orang konsumen $(36,67 \%)$ memberikan jawaban gula aren yang bagus adalah dengan aroma harum.

Ada 21 (70,00\%) orang konsumen yang mengatakan gula aren yang bagus adalah dengan rasa sangat manis. Sementara itu, ada 9 orang konsumen yang mengatakan gula aren dengan rasa manis, dari segi bentuk sebanyak 17 orang konsumen $(56,67 \%)$ mengatakan kriteria bentuk gula aren yang bagus adalah dengan bentuk bulat cekung, 13 orang mengatakan dengan bentuk gepeng $(43,33 \%)$.

Deskripsi mutu gula aren selanjutnya adalah dari segi kemasan. Seluruh konsumen 
menjawab ketika mereka membeli gula aren yang berada di pasar, kemasan yang digunakan untuk membungkus gula aren adalah menggunakan daun pisang. Namun ada dari beberapa konsumen pada saat membeli produk gula aren tersebut mereka mengharapkan agar kemasan yang digunakan untuk membungkus gula aren menggunakan kemasan yang lebih baik/bagus lagi. Agar produk gula aren yang berasal dari Kabupaten Kuantan Singingi bisa dikenal oleh seluruh masyarakat baik dari daerah itu sendiri ataupun dari daerah lain.

Hasil penelitian oleh Kusumawati (2010), deskripsi mutu dari segi kemasan menurut konsumen di Kecamatan Tebing Tinggi, Kab. Kepulauan Meranti adalah kemasan plastik putih tidak memberikan pengaruhyang berarti dalam pemasaran mie sagu. Walaupun hanya menggunakan plastikputih, tingkat konsumsi mie sagu tidak mengalami penurunan, karena mayoritasmasyarakat menilai mie sagu dari segi warna dan tekstur dan bukan darikemasannya.

\section{KESIMPULAN}

Pada aspek produksi faktor-faktor dominan yang mempengaruhi adalah luas panen padi sawah dan total tenaga kerja dalam usahatani, namun tidak ditemukan faktor yang mempengaruhi secara responsif. Pada aspek alokasi waktu kerja yaitu: Pertama, factor dominan yang mempengaruhi curahan kerja dalam usahatani adalah pendapatan dalam usaha, curahan kerja luar usaha dan angkatan kerja petani. Kedua, pada persamaan penggunaan tenaga kerja luar keluarga dalam usahatani dipengaruhi oleh produksi. Ketiga, factor dominan yang mempengaruhi curahan kerja luar usahatani adalah pendapatan luar usahatani, curahan kerja dalam usahatani, angkatan kerja petani dan pengalaman kerja petani. Pada aspek pendapatan, factor dominan yang mempengaruhi adalah curahan kerja luar usaha, angkatan kerja petani, umur petani dan pengalaman kerja petani. Pada aspek pengeluaran yaitu: Pertama, factor dominan yang mempengaruhi pengeluaran konsumsi pangan adalah pendapatan total petani dan jumlah anggota rumah tangga petani. Kedua, factor dominan yang mempengaruhi pengeluaran konsumsi non pangan adalah pendapatan total petani, investasi pendidikan dan tabungan rumah tangga petani. Ketiga, investasi pendidikan dipengaruhi oleh pendapatan total petani dan jumlah anak. Keempat, investasi usahatani dipengaruhi oleh pendapatan total petani, luas panen padi sawah dan investasi pendidikan. Kelima pengeluaran rekreasi dipengaruhi oleh pendapatan total petani, invetasi pendidikan, konsumsi total petani dan tabungan. Keenam, tabungan dipengaruhi oleh pendapatan total petani, konsumsi total petani, investasi pendidikan dan pengeluaran petani.

\section{DAFTAR PUSTAKA}

Badan Pusat Statistik. 2015. Kampar dalam Angka 2015. Badan Pusat Statistik Kabupaten Kampar, Kampar.

B. Swastha dan Irawan, (1999), Manajemen Pemasaran Modern, Edisi 2, Yogyakarta : Liberty.

Darmadi, S. 2010. Tinjauan Aspek Mutu Dalam Kegiatan Industri Pangan. Skripsi Departemen Ilmu dan Teknologi Pangan Fakultas Teknologi Pertanian Institut Pertanian Bogor. Bogor.

Koutsoyiannis, A. 1977.Theory of Econometrics. Harper and Row Publisher Inc., New York.

Mubyarto. 1994. Pengantar Ekonomi Pertanian. LP3ES. Jakarta

Soekartawi. 2005. Agribisnis Teori dan Aplikasi. Edisi Revisi. PT. Raja Grafindo Persada. Jakarta.

Soekartawi. 2001. Analisis Usahatani. UI Press. Jakarta.

Badan Standardisasi Nasional. 1995. Standar Nasional Indonesia. SNI 01-3820-1995. Sosis. Badan Standardisasi Nasional. Jakarta. 